\title{
The role of phenotype on ventilation and exercise capacity in patients affected by COPD: a retrospective study
}

\author{
Rocco F. Rinaldo, ${ }^{1}$ Michele Mondoni, ${ }^{1}$ Sofia Comandini, ${ }^{2}$ Pietro Lombardo, ${ }^{1}$ Beatrice Vigo, ${ }^{1}$ Silvia Terraneo, ${ }^{1}$ \\ Pierachille Santus, ${ }^{3}$ Stefano Carugo, ${ }^{4}$ Stefano Centanni, ${ }^{1}$ Fabiano Di Marco ${ }^{2}$ \\ ${ }^{1}$ Department of Health Sciences, University of Milan, Respiratory Unit, ASST Santi Paolo e Carlo, Milan \\ ${ }^{2}$ Department of Health Sciences, University of Milan, Respiratory Unit, ASST Papa Giovanni XXIII Hospital, Bergamo \\ ${ }^{3}$ Department of Biomedical and Clinical Sciences (DIBIC), University of Milan, Division of Respiratory Diseases, Luigi \\ Sacco University Hospital, Milan \\ ${ }^{4}$ Department of Health Sciences, University of Milan, Cardiology Unit, ASST Santi Paolo e Carlo, Milan, Italy
}

Background: The idea of phenotype in chronic obstructive pulmonary disease (COPD) has evolved in the last decades, and the importance of peculiar treatment strategies has now been acknowledged. Although dyspnea and exercise limitation are hallmarks of COPD, this aspect has never been fully explored in literature in terms of disease phenotype. The aim of the present study was to explore the relevance of clinical COPD phenotypes on exercise ventilation and maximal capacity.

Methods: In this observational cohort retrospective study we analyzed the data of 50 COPD patients who underwent cardiopulmonary exercise test, categorized as emphysematous $(n=29)$, and non-emphysematous $(n=21)$ according to a previously validated model.

Results: We found a significant difference in terms of $\mathrm{VE} / \mathrm{VCO}_{2}$ slope (median values 32.4 vs 28.0, $p=0.015$ ) and $\mathrm{VE} / \mathrm{VCO}_{2}$ ratio at nadir (median values $37 v s .33, p=0.004$ ), which resulted higher in emphysematous patients, who also presented lower $\mathrm{P}_{\mathrm{ET}} \mathrm{CO}_{2}$ values (median values 32.6 vs 35.6, $p=0.008$ ). In a subgroup of 31 tests which met the maximality criteria, emphysematous patients presented a significantly lower work rate at peak (median value $51 v s 72 \%$ predicted, $p=0.016$ ), and showed a lower peak oxygen consumption, although at the limit of significance (median values of 63 vs $85 \%$ predicted, $p=0.051$ ).

Conclusions: This study extends our knowledge about the characterization of the COPD phenotypical expression of disease, showing that patients affected by emphysema are more prone to ventilatory inefficiency during exercise, and that this is likely to be an important cause of their overall reduced exercise capacity.

Key words: COPD; cardiopulmonary exercise test; ventilation; exercise capacity; phenotype; emphysema.

Correspondence: Dr. Rocco F. Rinaldo, San Paolo Hospital, Via Antonio di Rudinì 8, 20142 Milano, Italy.

Tel. +39.02.81814 3025. E-mail: rocco.rinaldo@unimi.it

Contributions: All authors contributed extensively to the work presented in this paper. RFR, designed the study, collected the data, checked and analyzed the data, did a literature review and wrote the paper; MM, checked and analyzed the data, did a literature review and wrote the paper; PL, SCo, BV, collected the data; ST, checked and analyzed the data; SCa, SCe, MM, PS, supervised the analysis and edited the manuscript; FDM, designed the study, checked and analyzed the data, did a literature review and edited the manuscript. All authors discussed the results and implications and commented on the manuscript at all stages. All authors read and approved the final manuscript.

Conflict of interest: The Authors declare no conflict of interest.

Funding: This research received no specific grant from any funding agency in the public, commercial, or not-for-profit sectors.

Availability of data and materials: The data that support the findings of this study are available from the corresponding author upon reasonable request.

Ethics approval and consent to participate: This research was conducted in accordance with all relevant guidelines and procedures. The study was approved by the San Paolo Hospital-Milan Area 1 Ethics Committee. Informed consents were obtained from patients.

Consent for publication: The manuscript does not contain any individual person's data in any form. 


\section{Introduction}

The idea of phenotype in chronic obstructive pulmonary disease (COPD) has evolved in the last decades starting from a mere morphological and functional description, as in Burrows and colleagues pivotal works [1], coming to assume a wider meaning. In fact, many efforts have been spent to identify subgroups with key characteristics including the many aspects that concur to the wide variability of presentation in these patients: clinical features, physiology, imaging, response to therapy, decline in lung function, and survival. Although research is also relentlessly focused on defining the determinants of COPD in terms of genetics, many data are still lacking to clearly delineate a role for this aspect in the management of patients [2], underlining the importance of the clinical nature of phenotypization. The main aim becomes then to describe "clinical phenotypes", that include all the variables that the advances made in the study of the disease in terms of imaging technology, molecular biology, therapeutic targets and clinical outcomes [3] offer, highlighting the need to overcome $\mathrm{FEV}_{1}$ as the only physiological variable involved in diagnosis and treatment of the COPD population [4]. The importance of stratifying these patients and treat them differently has been acknowledged by the committees of several national statements and guidelines since the beginning of the current decade [5], suggesting that the management of patients with COPD can also be addressed in the light of the clinical phenotype. Although dyspnea and exercise capacity limitation are hallmarks of COPD [6], this aspect has never been fully explored in literature in terms of disease phenotype.

Various papers focused on exercise capacity in selected groups of patients defined by phenotypical characteristics (particularly emphysema) can be found in literature [7-10]. Although, to our knowledge, there is only one paper by Marquez-Martin and colleagues [11] reporting only a few data on peak exercise capacity measured through the gold standard, which is the cardiopulmonary exercise test (CPET) [12], comparing directly two groups of patients affected by COPD with different phenotypical expression (emphysematous and non-emphysematous). It is still an open question how much difference phenotype influence has on exercise capacity and in particular on ventilation [13]. It is then the purpose of the present study to explore the relevance of clinical COPD phenotypes in terms of maximal exercise capacity and ventilation, as measured thorough CPET.

\section{Methods}

\section{Protocol and study population}

This is an observational cohort retrospective analysis involving outpatients affected by COPD, who underwent CPET for clinical reasons or as part of observational studies as control group at our exercise laboratory at San Paolo Hospital in Milan (Italy) between March 2012 and May 2018. Local ethics committee approved the study. In our tertiary center all patients affected by COPD are evaluated routinely with body pletismography, and diffusing capacity of the lung for carbon monoxide $\left(\mathrm{DL}_{\mathrm{CO}}\right)$. Patients had an established diagnosis of COPD (i.e. post-bronchodilator $\mathrm{FEV}_{1} / \mathrm{FVC}<$ LLN, and history of exposure to tobacco smoke with no evidence of asthma or any other lung disease) [14]. Spirometric severity was defined according to the Global Initiative for Chronic Obstructive Lung Disease (GOLD) criteria [15]. All the patients met the criteria for the phenotype evaluation (see below). All the clinical data were obtained from medical records of the subjects, including medical history evaluation, and symptoms assessment.
Specifically, dyspnea was estimated using the Italian version of the modified Medical Research Council dyspnea scale (mMRC). Comorbidities were evaluated by Charlson comorbidity index, in which a higher score indicates greater coexisting conditions.

\section{Exercise and pulmonary function tests}

Symptom-limited, incremental, exercise testing was performed on an electronically braked cycle ergometer using the Vmax Spectra Cardiopulmonary Exercise Testing System (SensorMedics, Yorba Linda, USA) [12]. The rate of work rate increment $(\mathrm{W} / \mathrm{min})$ was identified on an individual basis according to expected exercise tolerance, and resting functional data. Ventilation (VE, L/min), oxygen uptake $\left(\mathrm{VO}_{2}, \mathrm{~L} / \mathrm{min}\right)$, carbon dioxide output $\left(\mathrm{VCO}_{2}, \mathrm{~L} / \mathrm{min}\right)$ end-tidal carbon dioxide tension $\left(\mathrm{P}_{\mathrm{ET}} \mathrm{CO}_{2}, \mathrm{mmHg}\right)$, respiratory frequency ( $\mathrm{fR}$, breaths/min), and tidal volume (VT, L) were averaged at $30 \mathrm{~s}$ intervals. Arterial oxygen saturation was measured by pulse oximetry $\left(\mathrm{SpO}_{2}, \%\right)$ noninvasively. Nadir $\mathrm{VE} / \mathrm{VCO}_{2}$ ratio was the lowest 30 -s average data point. We also collected the values of the slope and intercept of $\mathrm{VE}$ plotted versus $\mathrm{CO}_{2}$ output $\left(\mathrm{VCO}_{2}\right)$ during exercise, excluding data above the ventilatory compensation point [16]. Peak VE response was expressed as percentage of the estimated maximal voluntary ventilation (MVV, L/min), which was equal to $\mathrm{FEV}_{1} \times 35$. Breathing reserve $(\mathrm{BR}, \%)$ was computed as $M V V-V_{\text {peak }}$ and expressed as percentage of MVV. We considered as maximal a test meeting at least one of the following: i) respiratory exchange ratio (RER) at peak $\geq 1.15$; ii) breathing reserve $<15 \%$; iii) heart rate reserve $<15 \%$ with no evidence of heart rhythm disorders [12]. Spirometry, body pletismography and lung diffusion test were performed according to ATS/ERS statements (Med Graphics Elite spirometer, USA) [17-19].

\section{Evaluation of phenotype}

We used the CT score, published by Camiciottoli et al. [20], to evaluate the disease phenotype of our patients. This model, validated against the morphological gold standard that is the CT scan, is based on $\mathrm{DL}_{\mathrm{CO}}(\%$ predicted $)$, TLC ( $\%$ predicted $)$, and the presence of purulent sputum to identify three kind of prevalent involvement: emphysema, airway disease, and intermediate. We then grouped our patients in two groups for our final analysis: prevalent emphysema and non-emphysematous (including patients with prevalent airway disease and intermediate phenotype).

\section{Statistical analysis}

We decided to present all the quantitative data as median and interquartile range as the normality was not confirmed for all the variables, as assessed through the Wilk-Shapiro test. We used the Mann-Whitney U-test and the Chi-square test to compare respectively quantitative and qualitative data. Spearman's correlation was used to examine the association between variables. We calculated that a sample size of at least 15 patients per group was needed assuming that a difference of at least a standard deviation would exist if a phenotype was less efficient in terms of exercise ventilation, starting from the literature where a $\mathrm{VE} / \mathrm{VCO}_{2}$ slope value of $33 \pm 3$ was found in a group of mild-to-moderate emphysematous COPD patients [21]. A $p<0.05$ was considered statistically significant. Statistical tests were performed using the Statistical Package for Social Sciences (SPSS, Chicago IL, USA), ver. 23.0.

\section{Results}

We included in our analysis 50 patients (29 in the emphysema group, and 21 in the non-emphysema group). The main reason for undergoing CPET was pre-operative evaluation, followed by par- 
ticipation to research protocols, and dyspnea of unknown origin. Table 1 illustrates patient characteristics according to phenotype. We found a difference in $\mathrm{DL}_{\mathrm{CO}}$ that can be accounted as this being one of the variables determining the phenotype in the CT score. Moreover, we found a significant difference in BMI $(p=0.039)$, with, as expected, lower values for emphysematous patients.

\section{Overall ventilatory response during exercise}

The analysis of the whole sample of 50 patients are summarized in Table 2. There was a significant difference in terms of $\mathrm{VE} / \mathrm{VCO}_{2}$ slope, an effort-independent parameter of ventilatory efficiency, that resulted higher in emphysematous patients (Figure 1). $\mathrm{P}_{\mathrm{ET}} \mathrm{CO}_{2}$ was confirmed to be lower in this group (Figure 2), while $\mathrm{VE} / \mathrm{VCO}_{2}$ at nadir was higher. No difference was found in breathing reserve, tidal volume at peak or at rest, or in breathing frequency.

\section{Maximal exercise capacity}

Thirty-one tests met the maximality criteria, as previously described. Table 3 illustrates the effort-dependent variables, from maximal tests. Emphysematous patients presented a significantly lower work rate at peak (as percentage of predicted). This group also showed a lower peak oxygen consumption (percentage of predicted), although at the limit of significance $(p=0.051)$. We did not find differences in the other cardiovascular or metabolic variables. In terms of ventilatory response emphysematous patients featured a higher value of $\mathrm{VE} / \mathrm{VCO}_{2}$ at nadir, as well as a significantly lower end tidal pressure for carbon dioxide. $\mathrm{VE} / \mathrm{VCO}_{2}$ ratio at nadir showed a marked correlation with maximal oxygen consumption at peak (Figure 3; Sperman's $r=-0.658, p<0.01,43 \%$ of the variation explained).

\section{Discussion}

Two major findings come from our study: i) emphysematous patients show less ventilatory efficiency during exercise than the non-emphysematous; ii) emphysematous patients have an overall lower exercise capacity then the non-emphysematous.

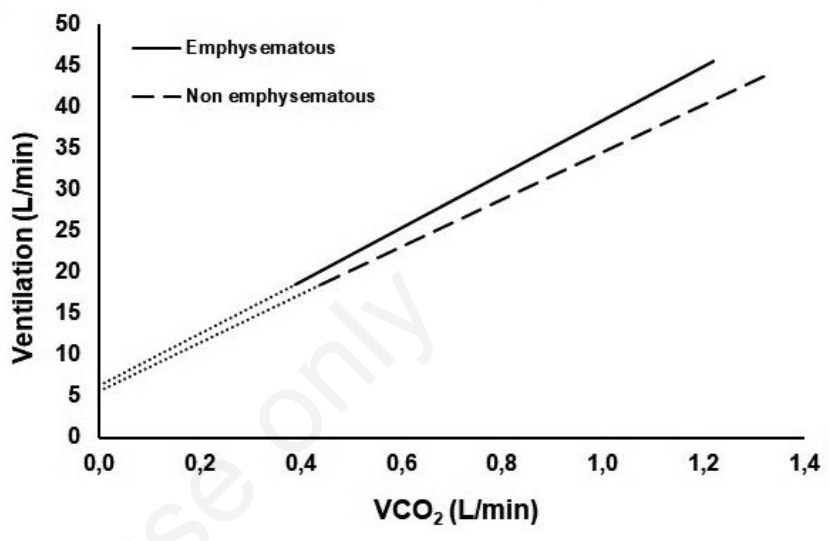

Figure 1. Graphical representation of the median values of $\mathrm{VE} / \mathrm{VCO}_{2}$ slope and intercept in the two groups during cardiopulmonary exercise test. $\mathrm{VCO}_{2}$, Carbon dioxide output; $\mathrm{VE} / \mathrm{VCO}_{2}$ slope median values and interquartile range: emphysematous 32.4 (29.4-35.3), non-emphysematous 28.0 (26.1-33.2); $p=0.015$. $\mathrm{VE} / \mathrm{VCO}_{2}$ intercept median values and interquartile range: emphysematous 6.3 (3.7-7.6), non-emphysematous 5.6 (4.2-6.4); $p=0.536$.

Table 1. Baseline characteristics of all patients according to phenotype.

\begin{tabular}{|c|c|c|c|}
\hline & Emphysematous (n=29) & Non-emphysematous ( $\mathrm{n}=21$ ) & $p$ \\
\hline Male, n (percentage) & $25(86 \%)$ & 17 (81\%) & 0.706 \\
\hline $\mathrm{BMI}, \mathrm{kg} / \mathrm{m}^{2}$ & $24.5(21.9-27.4)$ & $27.1(24.9-28.1)$ & $0.039 *$ \\
\hline Age, years & $70(61-74)$ & $71(64-75)$ & 0.345 \\
\hline $\mathrm{FEV}_{1}, \%$ predicted & $56(41-60)$ & $60(53-67)$ & 0.077 \\
\hline FVC, \%predicted & $86(68-94)$ & $76(65-95)$ & 0.529 \\
\hline TLC, \%predicted & $108(101-121)$ & $102(89-121)$ & 0.325 \\
\hline RV, \%predicted & $159(131-189)$ & $146(124-175)$ & 0.350 \\
\hline $\mathrm{DL}_{\mathrm{CO}}, \%$ predicted & $50(40-63)$ & $75(65-92)$ & $0.000^{*}$ \\
\hline $\mathrm{mMRC}^{\circ}$ & $1(1-2)$ & $1(1-1)$ & 0.976 \\
\hline $\operatorname{mMRC}(0 / 1 / 2 / 3 / 4)^{\circ}$ & $1 / 7 / 6 / 1 / 0$ & $1 / 8 / 2 / 0 / 0$ & 0.473 \\
\hline Charlson Index & $2(1-4)$ & $3(1-3)$ & 0.217 \\
\hline Ischemic heart disease & 3 & 1 & 0.632 \\
\hline Arrhythmia & 1 & 0 & 0.578 \\
\hline Heart failure & 2 & 0 & 0.504 \\
\hline Systemic arterial hypertension & 12 & 5 & 0.235 \\
\hline Diabetes & 6 & 2 & 0.440 \\
\hline Chronic kidney disease & 2 & 0 & 0.509 \\
\hline GOLD obstruction grade $(1 / 2 / 3 / 4)$ & $2 / 18 / 6 / 3$ & $2 / 15 / 4 / 0$ & 0.483 \\
\hline Reason for test (dyspnea/pre-operative/research) & $2 / 17 / 10$ & $0 / 9 / 12$ & 0.137 \\
\hline Reason for stopping (dyspnea/muscular fatigue/discomfort) & $10 / 16 / 2$ & $4 / 10 / 6$ & 0.093 \\
\hline
\end{tabular}

${ }^{\circ}$ Available for 26 patients; $\mathrm{FEV}_{1}$ forced expiratory volume in $1 \mathrm{~s}$; FVC, forced vital capacity; TLC, total lung capacity; RV, residual volume; $\mathrm{DL}_{\mathrm{CO}}$, diffusing capacity of the lung for carbon monoxide; $\mathrm{mMRC}$ modified medical research council scale for dyspnea; BMI, body mass index; GOLD, Global Initiative for Chronic Obstructive Lung Disease. ${ }^{*} p<0.05$. 
The relationship between the increase in VE and in $\mathrm{CO}_{2}$ output during exercise is of pivotal importance to explore the mechanisms of exercise intolerance in COPD; nevertheless, it requires a careful interpretation across the spectrum of severity of the disease, especially in terms of $\mathrm{VE} / \mathrm{VCO}_{2}$ slope and value of $\mathrm{VE} / \mathrm{VCO}_{2}$ ratio at nadir [13]. As a matter of fact, the relevance of the $\mathrm{VE} / \mathrm{VCO}_{2}$ slope as indicator of ventilatory efficiency per se, is matter of debate in literature [22]. Patients typically showing ventilatory inefficiency during exercise, but with a preserved ventilatory pump function such as in chronic heart failure, pulmonary arterial hypertension and chronic thromboembolic disease [23-26], display an increasing tendency to hyperventilation (expressed as higher values of $\mathrm{VE} / \mathrm{VCO}_{2}$ slope) as the disease progresses. This paradigm was found not to be so true in COPD [22], as in the majority of patients, the progression of the disease is accompanied by an increasing impairment in the capacity of producing ventilation in response to a stimulus, due to a reduced ventilatory mechanical capacity [10]. In more impaired patients the values of $\mathrm{VE} / \mathrm{VCO}$ are reduced (comparable to those of healthy subjects), meaning a mechanical constraint that prevents patients from increasing their ventilation.

Table 2. Overall ventilatory response during exercise in COPD patients according to phenotype.

\begin{tabular}{|c|c|c|c|}
\hline & Emphysematous ( $\mathrm{n}=29$ ) & Non-emphysematous ( $\mathrm{n}=21$ ) & $p$ \\
\hline Breathing reserve, $\%$ & $19(7-36)$ & $32(10-38)$ & 0.212 \\
\hline Ventilation peak absolute, $\mathrm{L}$ & $38.8(33.6-48.1)$ & $40.0(35.3-49.6)$ & 0.776 \\
\hline VEN CO $\mathrm{CO}_{2}$ slope & $32.4(29.4-35.3)$ & $28.0(26.1-33.2)$ & $0.015^{*}$ \\
\hline $\mathrm{P}_{\mathrm{ET}} \mathrm{CO}_{2}, \mathrm{mmHg}$ & $32.6(31.2-35.2)$ & $35.6(33.8-38.9)$ & $0.008^{*}$ \\
\hline $\mathrm{VE} / \mathrm{CO}_{2}$, intercept & $6.3(3.7-7.6)$ & $5.6(4.2-6.4)$ & 0.536 \\
\hline $\mathrm{VENCO}_{2}$ ratio at nadir, L/L & $37(35-42)$ & $33(31-37)$ & $0.004^{*}$ \\
\hline Tidal volume at rest, $\mathrm{L}$ & $0.780(0.635-0.865)$ & $0.720(0.550-0.915)$ & 0.467 \\
\hline Tidal volume at peak, $\mathrm{L}$ & $1.194(0.968-1.395)$ & $1.241(0.964-1.425)$ & 0.930 \\
\hline$\Delta$ Tidal volume peak-rest & $0.422(0.253-0.557)$ & $0.525(0.231-0.653)$ & 0.361 \\
\hline Breathing frequency at rest, breaths/min & $20(18-26)$ & $21(18-25)$ & 0.953 \\
\hline Breathing frequency at peak, breaths/min & $35(29-39)$ & $35(31-37)$ & 0.922 \\
\hline$\Delta$ Breathing frequency peak-rest & $10(8-17)$ & $13(8-16)$ & 0.484 \\
\hline VTpeak/FEV $_{1}$ & $0.90(0.75-1.02)$ & $0.80(0.73-0.92)$ & 0.331 \\
\hline VTpeak/FVC & $0.41(0.34-0.48)$ & $0.46(0.38-0.53)$ & 0.128 \\
\hline
\end{tabular}

$\mathrm{VE}$, ventilation; $\mathrm{VO}_{2}$, oxygen consumption; $\mathrm{VCO}_{2}$, carbon dioxide output; $\mathrm{VE}$, ventilation; $\mathrm{P}_{\mathrm{ET}} \mathrm{CO}_{2}$, end tidal pressure for carbon dioxide; $\mathrm{VT}$, tidal volume; $\mathrm{FEV}$, forced expiratory volume in $1 \mathrm{~s}$; $\mathrm{FVC}$, forced vital capacity. ${ }^{*} p<0.05$.

Table 3. Difference in terms of effort dependent variables from maximal tests according to phenotype.

\begin{tabular}{|c|c|c|c|}
\hline & Emphysematous $(\mathrm{n}=18)$ & Non-emphysematous $(\mathrm{n}=13)$ & $p$ \\
\hline $\mathrm{VO}_{2}$ peak absolute, $\mathrm{L}$ & $1.159(0.873-1.309)$ & $1.293(1.007-1.581)$ & 0.242 \\
\hline $\mathrm{VO}_{2}$ peak absolute, $\mathrm{ml} / \mathrm{min} / \mathrm{kg}$ & $15.9(13.2-19.0)$ & $19.8(12.9-21.6)$ & 0.312 \\
\hline $\mathrm{VO}_{2}$ peak, \%predicted & $63(52-78)$ & $85(63-95)$ & 0.051 \\
\hline Work peak absolute, $\mathrm{W}$ & $72(43-82)$ & $89(60-107)$ & 0.106 \\
\hline Work peak, \%predicted & $51(43-70)$ & $72(69-86)$ & $0.016^{*}$ \\
\hline Respiratory Exchange Ratio at peak & $1.08(0.99-1.16)$ & $1.11(0.99-1.20)$ & 0.594 \\
\hline Heart rate peak, \%predicted & $86(71-94)$ & $89(76-94)$ & 0.755 \\
\hline Oxygen pulse peak absolute, $\mathrm{ml} /$ beat & $9(8.1-10.1)$ & $10.0(8.0-11.7)$ & 0.346 \\
\hline Oxygen pulse peak, \%pred & $76(71-93)$ & $98(78-114)$ & 0.124 \\
\hline Breathing reserve, $\%$ & $9(1-20)$ & $26(7-37)$ & 0.106 \\
\hline Ventilation peak absolute, $\mathrm{L}$ & $44.3(35.4-54.3)$ & $40.0(35.9-56.4)$ & 0.798 \\
\hline VENCO ${ }_{2}$ nadir, L/L & $36(33-43)$ & $32(29-34)$ & $0.004^{*}$ \\
\hline PET CO, mmHg & $33(30-35)$ & $36(34-41)$ & $0.012^{*}$ \\
\hline Tidal volume peak, L & $1.222(0.969-1.447)$ & $1.241(1.017-1.425)$ & 1.000 \\
\hline Breathing frequency peak, breaths/min & $37(30-40)$ & $35(31-39)$ & 0.567 \\
\hline$\Delta$ Tidal volume peak-rest, $\mathrm{L}$ & $0.432(0.297-0.571)$ & $0.604(0.416-0.722)$ & 0.125 \\
\hline$\Delta$ Breathing frequency peak-rest, breaths/min & $11(8-20)$ & $11(7-18)$ & 0.798 \\
\hline VTpeak/FEV $_{1}$ & $0.92(0.80-1.02)$ & $0.80(0.73-0.94)$ & 0.293 \\
\hline VTpeak/FVC & $0.44(0.39-0.51)$ & $0.48(0.41-0.55)$ & 0.125 \\
\hline
\end{tabular}

$\mathrm{VE}$, ventilation; $\mathrm{VO}_{2}$, oxygen consumption; $\mathrm{VCO}_{2}$, carbon dioxide output; $\mathrm{VE}$, ventilation; $\mathrm{P}_{\mathrm{ET}} \mathrm{CO}_{2}$, end tidal pressure for carbon dioxide; $\mathrm{VT}$, tidal volume; $\mathrm{FEV}$, forced expiratory volume in $1 \mathrm{~s}$; $\mathrm{FVC}$, forced vital capacity. ${ }^{*} p<0.05$. 
Particularly, the subject of emphysematous patients was explored by different authors in literature: Crisafulli and colleagues [9] demonstrated that, in a cohort of mild-to-moderate patients, the values of $\mathrm{VE} / \mathrm{VCO}_{2}$ slope increase in patients with a higher share of low attenuation areas $(<950 \mathrm{HU})$ at the CAT scan, while Paoletti and colleagues [8] showed that in patients with a more severe disease (evaluated as percentage of emphysema at the CAT, attenuation ranging between -1024 and $-910 \mathrm{HU}$ ) this values tend to flatten, and decrease.

In our study, emphysematous patients showed a higher $\mathrm{VE} / \mathrm{VCO}_{2}$ slope compared to non-emphysematous, as well as a higher $\mathrm{VE} / \mathrm{VCO}_{2}$ ratio at nadir in maximal tests. We interpreted this result as an indicator of a more pronounced ventilatory inefficiency in the former group. As a matter of fact, in our sample most patients were in GOLD obstruction class 1 or 2 (meaning an $\mathrm{FEV}_{1}$ $>50 \%$ of predicted), thus possibly not exhibiting an extremely marked mechanical limitation. This is consistent with the aforementioned study of Crisafulli et al. (9), and also with the findings of Jones et al. [21] who showed that in a group of mild-to-moderate COPD patients the higher the extent of emphysema (quantified as percentage of area with an attenuation lower than $950 \mathrm{HU}$ at $\mathrm{HR}$ CAT scan) the higher the $\mathrm{VE} / \mathrm{VCO}_{2}$ ratio at nadir. Supporting this, the evidence that in our sample those who reached a lower $\mathrm{VE} / \mathrm{VCO}_{2}$ value at nadir (meaning a better ventilation/perfusion matching), exercised more, reaching a higher peak $\mathrm{VO}_{2}$ (Figure 3). The term ventilatory efficiency relates to the ability of the lung to clear the physiologic carbon dioxide and is determined by two factors, the share of dead space (Vd $/ \mathrm{Vt}$ phys) and $\mathrm{PaCO}_{2}$, and is expressed through the modified Bohr equation: $\mathrm{VE} / \mathrm{VCO}_{2}=$ $\mathrm{k} / \mathrm{PaCO}_{2}{ }^{*}(1-\mathrm{Vd} / \mathrm{Vt})$, meaning that high values should be reflective of an increased dead space and/or decreased $\mathrm{PaCO}_{2}$ set-point. It is possible that the difference we found in ventilatory efficiency is due to a higher dead space [27], typical of the parenchymal structural abnormalities caused by emphysema. This interpretation seems to be more likely than an alteration of the $\mathrm{CO}_{2}$ set point driving to hypocapnia, given the tendency of COPD patients to develop a higher tolerance to carbon dioxide as the disease progresses instead [28]. Surely, the possible role of dynamic hyperinflation (DH) should be discussed, as a component of the ventilatory inefficiency during exercise. A subgroup of emphysematous patients called "emphysema-hyperinflated" patients is described in literature [29], who are characterized by high total lung capacity (TLC) and residual volume (RV) at rest, and is associated to a higher percentage of emphysema. While many studies showed a correlation among hyperinflation at rest and indices of dyspnea and reduced daily physical activity [30,31], the direct role of dynamic hyperinflation remains debated as Guenette and colleagues did not report any significant difference at CPET between a group of proven emphysematous "dynamic hyperinflators" and patients who did not, in terms of exercise capacity or symptoms, although data about $\mathrm{VE} / \mathrm{VCO}_{2}$ slope or $\mathrm{VE} / \mathrm{VCO}_{2}$ at nadir were not provided in the paper [32]. No conclusion can be taken from our study as we did not evaluate the presence of DH. A heightened ventilatory drive in emphysematous could also be related to different stimuli coming from peripheral muscles involved during exercise, which are more compromised in this group of patients, as demonstrated by Marquez-Martin and colleagues [11]. Nevertheless, no conclusion from our sample can be taken, as no data about blood gases were recorded for our patients. Emphysematous patients show also a significantly lower end tidal pressure for $\mathrm{CO}_{2}$ at peak compared to non-emphysematous. In this context this can be interpreted as expression of a higher dilution of the gas in the expired volume due to heightened ventilatory drive [33]. Still, this testify their capacity of increasing ventilation.

The usefulness of $\mathrm{VE} / \mathrm{VCO}_{2}$ relationship as an outcome for intervention remains anecdotal in literature and a minimal clinically important difference has not been identified yet, in COPD [34]. Our study may suggest this outcome to be worth to be further explored in this specific group of patients, also considering the correlation between $\mathrm{VE} / \mathrm{VCO}_{2}$ and the extent of emphysema on the CT scan [8].

In terms of maximal exercise capacity our sample shows a lower level of work at peak reached by the emphysematous patients (expressed as percentage of predicted), with the peak oxygen consumption at the limits of statistical significance $(p=0.051)$. These findings are consistent with the Marquez-Martin paper, in which are reported oxygen consumption at peak and power from maximal exercise tests [11] in two groups of patients according to phenotypes (emphysematous and non-emphysematous), with similar values of lung function at rest. This study reported a lower

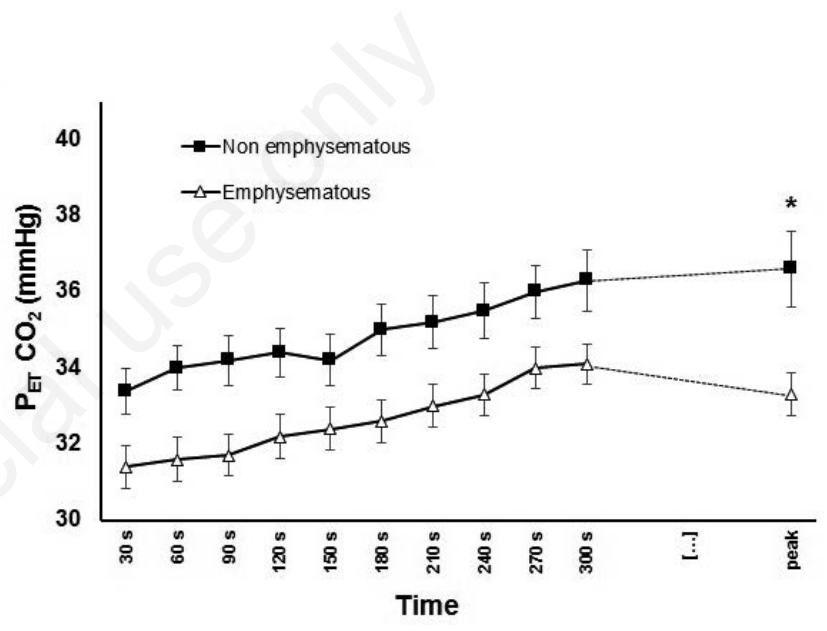

Figure 2. Graphical representation of $\mathrm{P}_{\mathrm{ET}} \mathrm{CO}_{2}$ in the two groups during cardiopulmonary exercise test. ${ }^{*} p<0.05 . \mathrm{P}_{\mathrm{ET}} \mathrm{CO}_{2}$, end tidal pressure for carbon dioxide. Median values and interquartile range of $\mathrm{P}_{\mathrm{ET}} \mathrm{CO}_{2}$ at peak: emphysematous 33 (30-35), nonemphysematous 36 (34-41); $p=0.012$. No significant differences between $\mathrm{P}_{\mathrm{ET}} \mathrm{CO}_{2}$ at other time points at the Mann-Whitney $U$ test with Bonferroni adjustment for multiple measures.

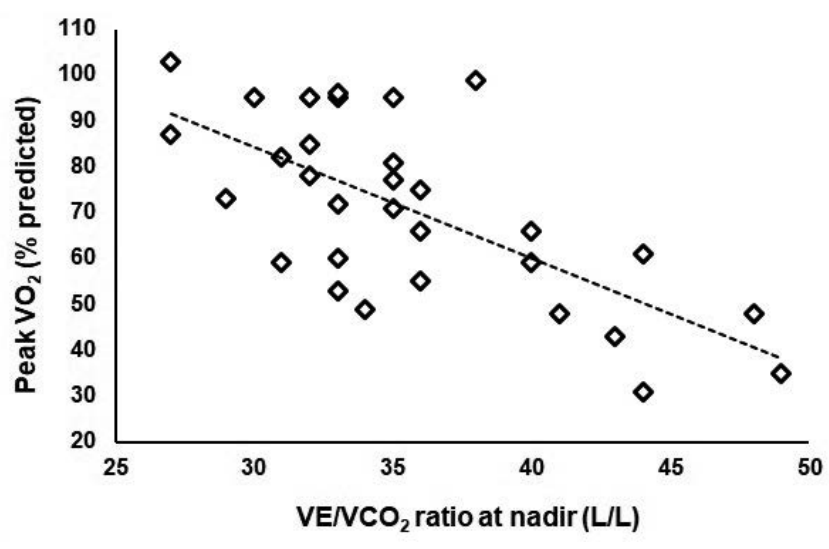

Figure 3. Relationship between peak exercise capacity and the carbon dioxide equivalent at nadir during cardiopulmonary exercise test. $\mathrm{VO}_{2}$, oxygen consumption; $\mathrm{VCO}_{2}$, carbon dioxide output; VE, Ventilation. Spearman's $r=-0.658, p<0.01,43 \%$ of the variation explained. 
power $(\mathrm{W})$ at peak in emphysematous patients, not reaching a significance in $\mathrm{VO}_{2}$. This data highlight the importance of the evaluation of the functional impairment related to the disease through the assessment of overall exercise capacity at the CPET, which Chen and colleagues [7] showed to worsen in cohort of COPD patients, as the extent of emphysema at the CT increases. MarquezMartin and colleagues found also that emphysematous subjects had a lower BMI, which we confirmed, and a difference in peripheral muscle strength, which was reduced in this group. With our study we add an inefficiency in ventilation to the factors contributing to a reduced exercise capacity in patients affected by COPD and characterized by an emphysematous phenotype, compared to non-emphysematous patients.

A number of potential limitations of this study deserve discussion: the fact that most of our patients are mild-to-moderate in terms of disease burden does not allow to extend our finding to every COPD subject. Moreover, we lack data about symptoms (i.e., BORG scale for dyspnea and fatigue) during exercise; this does not let us relate our findings in terms of physiology to patients' perception. In addition, there is for sure the bias of the retrospective nature of this study, with non-consecutive patients that underwent CPET also for clinical reasons, reducing the external validity of our final results.

\section{Conclusion}

Our study extends our knowledge about the characterization of the COPD phenotypical expression of disease, showing that patients affected by emphysema are more prone to ventilatory inefficiency during exercise, and that this is likely to be an important cause of their overall reduced exercise capacity. Cardiopulmonary exercise testing is a useful tool that provides a deeper insight into pathophysiology and phenotypical definition of COPD patients. The usefulness of some variables as outcome for therapeutic intervention, in particular $\mathrm{VE} / \mathrm{VCO}_{2}$ slope [3], is worth to be further explored, especially in this specific and selected cluster of patients.

\section{Abbreviations}

COPD: Chronic obstructive pulmonary disease; CPET: Cardiopulmonary exercise test; FEV $V_{1}$ : Forced expiratory volume in $1 \mathrm{~s} ; D L_{C O}$ : Diffusing capacity of the lung for carbon monoxide; BMI: Body mass index; GOLD: Global Initiative for Chronic Obstructive Lung Disease; $\mathrm{VO}_{2}$ : Oxygen consumption; $\mathrm{VCO}_{2}$ : Carbon dioxide output; VE: Ventilation; $\mathrm{P}_{E T} \mathrm{CO}_{2}$ : End tidal pressure for carbon dioxide; $\mathrm{DH}$ : dynamic hyperinflation.

\section{References}

1. Burrows B, Fletcher CM, Heard BE, Jones NL, Wootliff JS. The emphysematous and bronchial types of chronic airways obstruction. Lancet 1966;287:830-5.

2. Agustí A, Hogg JC. Update on the pathogenesis of chronic obstructive pulmonary disease. N Engl J Med 2019;381:1248-56.

3. Han MLK, Agusti A, Calverley PM, Celli BR, Criner G, Curtis JL, et al. Chronic obstructive pulmonary disease phenotypes: The future of COPD. Am J Respir Crit Care Med 2010;182: 598-604.

4. Lange P, Halpin DM, O'Donnell DE, Macnee W. Diagnosis, assessment, and phenotyping of COPD: beyond FEV1. Int J Chron Obstruct Pulmon Dis 2016;11 Spec Iss:3-12. doi:
10.2147/COPD.S85976.

5. Miravitlles M, Vogelmeier C, Roche N, Halpin D, Cardoso J, Chuchalin AG, et al. A review of national guidelines for management of COPD in Europe. Eur Respir J 2016;47:625-37.

6. Di Marco F, Terraneo S, Job S, Rinaldo RF, Sferrazza Papa GF, Roggi MA, et al. Cardiopulmonary exercise testing and second-line pulmonary function tests to detect obstructive pattern in symptomatic smokers with borderline spirometry. Respir Med 2017;127:7-13.

7. Chen LF, Wang CH, Chou PC, Ho S, Joa WC, Sheng TF, et al. Association between emphysema score, six-minute walk and cardiopulmonary exercise tests in COPD. Open Respir Med J 2012;6:104-10.

8. Paoletti P, De Filippis F, Fraioli F, Cinquanta A, Valli G, Laveneziana P, et al. Cardiopulmonary exercise testing (CPET) in pulmonary emphysema. Respir Physiol Neurobiol 2011; 179:167-73.

9. Crisafulli E, Alfieri V, Silva M, Aiello M, Tzani P, Milanese G, et al. Relationships between emphysema and airways metrics at high-resolution computed tomography (HRCT) and ventilatory response to exercise in mild to moderate COPD patients. Respir Med 2016;117:207-14.

10. Teopompi E, Tzani P, Aiello M, Gioia MR, Marangio E, Chetta A. Excess ventilation and ventilatory constraints during exercise in patients with chronic obstructive pulmonary disease. Respir Physiol Neurobiol 2014;197:9-14.

11. Márquez-Martín E, Ramos PC, López-Campos JL, Gotarredona M del PS, Herrero SN, Aguilar RT, et al. Components of physical capacity in patients with chronic obstructive pulmonary disease: Relationship with phenotypic expression. Int J Chron Obstruct Pulmon Dis 2011;6:105-12.

12. American Thoracic Society, American College of Chest Physicians. ATS/ACCP Statement on cardiopulmonary exercise testing. Am J Respir Crit Care Med 2003;167:211-77. Erratum in: Am J Respir Crit Care Med 2003;1451-2. Comment in: ATS/ACCP statement on cardiopulmonary exercise testing. [Am J Respir Crit Care Med 2003]

13. Neder JA, Berton DC, Arbex FF, Alencar MC, Rocha A, Sperandio PA, et al. Physiological and clinical relevance of exercise ventilatory efficiency in COPD. Eur Respir J 2017;49:1-13.

14. Pellegrino R, Viegi G, Brusasco V, Crapo RO, Burgos F, Casaburi R, et al. Interpretative strategies for lung function tests. Eur Respir J 2005;26:948-68.

15. Singh D, Agusti A, Anzueto A, Barnes PJ, Bourbeau J, Celli $\mathrm{BR}$, et al. Global strategy for the diagnosis, management, and prevention of chronic obstructive lung disease: the GOLD science committee report 2019. Eur Respir J 2019;53. pii: 1900164.

16. Sun XG, Hansen JE, Garatachea N, Storer TW, Wasserman K. Ventilatory efficiency during exercise in healthy subjects. Am J Respir Crit Care Med 2002;166:1443-8.

17. MacIntyre N, Crapo RO, Viegi G, Johnson DC, van der Grinten CPM, Brusasco V, et al. Standardisation of the singlebreath determination of carbon monoxide uptake in the lung. Eur Respir J 2005;26:720-35.

18. Miller MR, Hankinson J, Brusasco V, Burgos F, Casaburi R, Coates A, et al. Standardisation of spirometry. Eur Respir J 2005;26:319-38.

19. Wanger J, Clausen JL, Coates A, Pedersen OF, Brusasco V, Burgos F, et al. Standardisation of the measurement of lung volumes. Eur Respir J 2005;26:511-22.

20. Camiciottoli G, Bigazzi F, Paoletti M, Cestelli L, Lavorini F, Pistolesi M. Pulmonary function and sputum characteristics predict computed tomography phenotype and severity of 
COPD. Eur Respir J. 2013;42(3):626-35.

21. Jones JH, Zelt JT, Hirai DM, Diniz C V., Zaza A, O'Donnell DE, et al. Emphysema on thoracic CT and exercise ventilatory inefficiency in mild-to-moderate COPD. COPD 2017;14:210-8.

22. Neder JA, Arbex FF, Alencar MCN, O’Donnell CDJ, Cory J, Webb KA, et al. Exercise ventilatory inefficiency in mild to end-stage COPD. Eur Respir J 2015;45:377-87.

23. Malhotra R, Bakken K, D'Elia E, Lewis GD. Cardiopulmonary exercise testing in heart failure. JACC Heart Fail 2016;4:607-16.

24. Apostolo A, Laveneziana P, Palange P, Agalbato C, Molle R, Popovic D, et al. Impact of chronic obstructive pulmonary disease on exercise ventilatory efficiency in heart failure. Int $\mathrm{J}$ Cardiol 2015;189:134-40. A

25. Zhai Z, Murphy K, Tighe H, Wang C, Wilkins MR, Gibbs JSR, et al. Differences in ventilatory inefficiency between pulmonary arterial hypertension and chronic thromboembolic pulmonary hypertension. Chest 2011;140:1284-91.

26. McCabe C, Deboeck G, Harvey I, Ross RM, Gopalan D, Screaton $\mathrm{N}$, et al. Inefficient exercise gas exchange identifies pulmonary hypertension in chronic thromboembolic obstruction following pulmonary embolism. Thromb Res 2013;132: 659-65.

27. Calverley P. Understanding breathlessness in mild chronic obstructive pulmonary disease. Am J Respir Crit Care Med 2008;177:564-5.
28. Poon CS, Tin C, Song G. Submissive hypercapnia: Why COPD patients are more prone to $\mathrm{CO} 2$ retention than heart failure patients. Respir Physiol Neurobiol 2015;216:86-93.

29. Dubé BP, Guerder A, Morelot-Panzini C, Laveneziana P. The clinical relevance of the emphysema-hyperinflated phenotype in COPD. COPD Res Pract 2016;2:1-11.

30. Lahaije AJMC, Van Helvoort HAC, Dekhuijzen PNR, Vercoulen JH, Heijdra YF. Resting and ADL-induced dynamic hyperinflation explain physical inactivity in COPD better than FEV1. Respir Med 2013;107:834-40.

31. Garcia-Rio F, Lores V, Mediano O, Rojo B, Hernanz A, LópezCollazo E, et al. Daily physical activity in patients with chronic obstructive pulmonary disease is mainly associated with dynamic hyperinflation. Am J Respir Crit Care Med 2009;180: 506-12.

32. Guenette JA, Webb KA, O'Donnell DE. Does dynamic hyperinflation contribute to dyspnoea during exercise in patients with COPD? Eur Respir J 2012;40:322-9.

33. Bussotti M, Magrì D, Previtali E, Farina S, Torri A, Matturri $\mathrm{M}$, et al. End-tidal pressure of $\mathrm{CO} 2$ and exercise performance in healthy subjects. Eur J Appl Physiol 2008;103:727-32.

34. Puente-Maestu L, Palange P, Casaburi R, Laveneziana P, Maltais F, Neder JA, et al. Use of exercise testing in the evaluation of interventional efficacy: An official ERS statement. Eur Respir J 2016;47:429-60.

Received for publication: 8 November 2019. Accepted for publication: 10 January 2020.

This work is licensed under a Creative Commons Attribution-NonCommercial 4.0 International License (CC BY-NC 4.0).

CCopyright: the Author(s), 2020

Licensee PAGEPress, Italy

Multidisciplinary Respiratory Medicine 2020; 15:476

doi:10.4081/mrm.2020.476 